\title{
An Ex-Post Investigation Of Interest Rate Parity In Asian Emerging Markets
}

Bahram Adrangi, (E-mail: adrangi@up.edu), University of Portland

Kambiz Raffiee'(E-mail: raffiee@umr.edu), University of Nevada, Reno

Todd M. Shank, (E-mail: tshank@stpt.usf.edu), University of South Florida, St. Petersburg

\begin{abstract}
This paper investigates the uncovered interest parity theory for the three emerging markets of Korea, the Philippines, and Thailand. The study provides evidence on the efficiency of the currency markets of these economies. In this paper we test for the uncovered interest parity because futures markets for currencies of most emerging markets are not well developed. Furthermore, short- term exchange rate supply and demand are often dominated by the uncovered international investments. Several statistical tests are applied in an attempt to detect evidence of uncovered interest parity. We find there is evidence that the currencies of higher interest rate emerging economies tend to depreciate in the future spot market. However, our test results indicate that this relationship does not support the uncovered interest parity strictly. Arbitrage opportunities remain for a longer periods than predicted by the uncovered interest parity. Furthermore, these abnormal gains are not random and could be predicted by a well designed econometric model. These findings are consistent with empirical findings surrounding uncovered interest parity for mature markets of the world.
\end{abstract}

\section{INTRODUCTION}

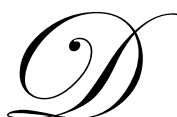

ivergent views exist regarding the question of how interest rate differentials among foreign countries relate to corresponding exchange rate differentials among those same economies. Interest rate parity (IRP) theory suggests that if interest rates are higher in one country than they are in another, the former country's currency will sell at a discount in the forward market (Van Horne, 1998). In other words, interest rate differentials and forward-spot exchange rate differentials should offset one another. If not, opportunities for profit by engaging in covered interest arbitrage would exist, although profits must be sufficiently large enough to cover transactions costs and other market frictions.

Several studies over the past two decades have examined the validity of interest rate parity in major world markets. Most of these studies have focused on countries with established forward financial markets in foreign currencies since these data are required to test "covered" IRP. The expectation is that the level of informational efficiency of these major markets is higher than other (less established) markets, making IRP more probable and opportunities to earn economic profits from covered interest arbitrage less likely. Moreover, financial market frictions such as the regulatory and political barriers among established markets have decreased over this period, further reducing arbitrage opportunities in foreign exchange markets. In testing the validity of IRP in emerging markets where no forward markets in currencies exists, "uncovered" IRP is used where the question is whether the change in the actual exchange rate between two countries equals that previously implied by the interest rate differential (Van Horne, 1998). The current practical relevance of this issue is that many large hedge funds now in operation seek to exploit market repricings across currencies. Such attempts to earn economic profits should be more risky, but also potentially more beneficial, in less efficient markets like the Asian emerging markets of Korea, the Philippines, and Thailand.

\section{BACKGROUND AND LITERATURE REVIEW}

Recent summaries of empirical evidence (Van Horne, 1998) show support for covered IRP among the United States, Japan, and most European countries in that there is generally an offsetting relationship between interest rates and 
the forward exchange rate relative to the spot rate, and that the cost of hedging offsets any yield advantage. Specifically, studies such as Rhee and Chang (1992), and Abeysekera and Turtle (1995), find that major global markets are efficient in the sense that profit opportunities from traditional covered interest arbitrage were rarely available in the 1980s and early 1990s. This is due to an (almost) absence of imperfections among these major economies. Most studies also show that IRP is stronger for short-term rates and weakens with longer maturities. However, empirical studies of uncovered IRP show mixed results.

Tests of the unbiased expectations hypothesis are used to study uncovered interest parity. Bakaert and Hodrick (1993) conclude that uncovered IRP did not hold through the early 1990s as high- interest-rate countries provided a higher net return, taking account of exchange rate changes, than did low interest rate countries. In other words, currency values of high interest rate countries did not depreciate fast enough to offset their yield advantages. Liu and Maddala (1992) also tested the unbiased expectations theory and concluded that the predictor is biased so covered interest parity doesn't hold and that the efficiency of the major currency markets of Japan, Germany, Great Britain, and Switzerland is questionable. Van Horne (1998) summarized evidence of test of uncovered IRP in the mid 1990s as being "less clear", where the IRP equality "more nearly prevailed". Assuming observed exchange rate differentials are beginning to exhibit a closer relationship with the previous interest rate differential in major markets, several additional questions arise. First, What is the relationship for non-major markets in the rest of world, in particular, those emerging markets in the Asian region (and how does this relationship differ from earlier studies of major global markets)? The prior studies leave the question of whether uncovered interest parity exists in non-major currency markets in post-1990 periods. It is likely that with today's technologically advanced markets, there is less likelihood of finding mispricings in the currency markets of established global economies. However, in emerging financial markets where price information moves more slowly, there should be more opportunities to arbitrage price discrepancies in currency values.

Second, what is the difference from studies of covered, as opposed to uncovered, parity? There is no organized futures or forward markets for most emerging market currencies, although it may be possible to secure a covered position in some of the more developed markets in this group through "tailor made" forward contracts. Even though an investor can occasionally find these arrangements, the lack of market price information leads to illiquidity in this type of futures contract. So, there is no forward market, therefore testing covered interest rate parity would be difficult, if not impossible, for emerging markets. Moreover, given that currency traders engage in asset balancing based on expected future currency values, the testing of uncovered interest parity may be of more interest. This is because uncovered interest arbitrage links spot currency rates, expected future currency rates, and short term interest rates between various markets. It makes sense that uncovered interest rate parity be empirically examined for emerging markets.

If the uncovered markets are not efficient, there are opportunities for and hedge fund managers and other speculators to find and exploit market mispricings. Such opportunities are assumed not to exist in the more efficient currency markets like those in the world's more established economies. If we find that uncovered parity does not hold, then we conclude that the Asian emerging markets of Thailand, Phillipines, and Korea are not completely efficient, and therefore offer arbitrage opportunities. It is likely that these opportunities persist because the underlying country risk of each of these currency markets reduces the number of speculators willing to participate in substantially informationally inefficient markets. The findings of this paper are relevant for emerging economy policy makers, as they try to become more integrated in the global economy. Market fundamentals that result in market inefficiencies and country risk, may be obstacles for foreign investments in emerging markets.

The expectation is that since emerging markets are less integrated with other established markets and informational efficiency is therefore lower, then IRP is less likely to be valid in Korea, Philippines, and Thailand. Moreover, since market imperfections/frictions such as transactions costs, capital constraints, and risk premia are more likely in these markets, the potential for economic profits from uncovered interest arbitrage holds greater promise for speculators such as hedge fund managers.

The objective of our paper is to test the uncovered interest parity theory for the Asian emerging markets of Korea, Philippines, and Thailand. Specifically, we attempt to answer the research questions posed above. If capital is mobile, then capital flows should equalize expected rates of return on those countries' assets regardless of exchange rate risk. The results, thus, provide data on the efficiency of the currency markets of three Asian emerging markets in recent periods. The findings of this paper are relevant for emerging economy policy makers, as they try to become 
more integrated in the global economy. The paper proceeds as follows. Section II develops the theoretical model. Section III discusses the methodology and the data we use. Section IV presents our results. Section V discusses our conclusions.

\section{THE THEORETICAL MODEL}

Uncovered interest parity is based on the premise that the expected rate of appreciation of the spot exchange rate value of a currency is equal to the difference in interest rates. Uncovered international investments involve investing in foreign currency denominated financial assets without hedging in futures markets. That is, the investment proceeds in a future time are converted back to the domestic currency at the prevailing spot currency exchange rates in the future. Therefore, the investment is exposed to exchange rate risk.

Let us assume that the current exchange rate of a currency in terms of foreign currency is $\mathrm{er}_{\mathrm{s}}$, the expected future spot rate is denoted by $e_{\mathrm{e}}$, and the domestic and foreign short-term interest rates are denoted by $i_{d}$ and $i_{f}$. A domestic investor who converts a sum in domestic currency to foreign currency and invests that in a short -term foreign bond will receive

$\left(1 / \mathrm{er}_{\mathrm{s}}\right) *\left(1+\mathrm{i}_{\mathrm{f}}\right)$.

Upon receiving the sum in equation (1), the investor, converts the amount received back to domestic currency using the spot exchange rate markets. Therefore, the amount received in domestic currency is given by equation (2) as

$\left(\mathrm{er}_{\mathrm{e}} / \mathrm{er}_{\mathrm{s}}\right) *\left(1+\mathrm{i}_{\mathrm{f}}\right)$.

The expected uncovered interest differential (EUID) in favor of the foreign investment is given by

EUDI $=\left(e_{\mathrm{e}} / \mathrm{er}_{\mathrm{s}}\right) *\left(1+\mathrm{i}_{\mathrm{f}}\right)-\left(1+\mathrm{i}_{\mathrm{d}}\right)$.

Manipulating equation (3) and assuming that forward expected exchange rate premium is given by $\left(\mathrm{er}_{\mathrm{e}}-\mathrm{er}_{\mathrm{s}}\right) / \mathrm{er}_{\mathrm{s}}=\mathrm{FP}$, we arrive at equation (4), which will be the basis for our empirical tests.

$\mathrm{EUDI}=\mathrm{FP}+\left(\mathrm{i}_{\mathrm{f}}-\mathrm{i}_{\mathrm{d}}\right)$.

Equation (4) states that depending on the FP and the foreign and the domestic interest rate differentials, investors determine the market to invest. As investors adjust their portfolio according to equation (4), short run supply and demand conditions for the domestic and foreign currencies in the spot market change. This leads to exchange rate adjustments in the spot market. The transactions in the spot market stop when the arbitrage opportunities have been eliminated through spot exchange rate adjustments. Therefore, EUDI is forced to zero and we have the following condition

$\mathrm{FP}+\left(\mathrm{i}_{\mathrm{f}}-\mathrm{i}_{\mathrm{d}}\right)=0$.

Equation (5) may be written as

$\left(e r_{e}-e r_{s}\right) / e r_{s}=-\left(i_{f}-i_{d}\right)$.

Equation (6) states that the expected depreciation in the exchange rate is equal to the difference between the foreign and the domestic interest rates. That is, if the foreign short-term rate exceeds the domestic short-term interest rate, then the value of the foreign currency in the future spot market is expected to fall and vice versa. In equilibrium, the exchange rate depreciation eliminates any additional interest income in the foreign market. This condition is known as the uncovered interest parity. The empirical formulation of equation (6) is expresses in equation (7) and will be estimated and discussed shortly.

$\mathrm{FP}_{\mathrm{t}}=\alpha+\beta \mathrm{DR}_{\mathrm{t}}+\mathrm{u}$ 
Where FP and RD represent exchange rate forward premium and rate differential between the short term foreign and the U.S. rates, respectively. The coefficient $\beta$ is expected to have a negative sign with magnitude equal to one indicating that the exchange rate depreciation is equal to the negative of the rate differentials.

Testing uncovered interest parity is made complicated by the lack of information on the actual exchange rate expectations that market participants form. One approach is to test the hypothesis on the ex post basis. Then actual expost exchange rates in the future are employed to represent the expected future exchange rates. If expected uncovered returns are at parity, then in a large sample of investments, the actual uncovered differentials should be random with an expected value of zero. Several studies have shown that the actual uncovered differentials are not random and in many occasions are not zero on average.

\section{DATA AND METHODOLOGY}

Monthly data from June 1981, May 1978, and January 1976, through January 1997 for the U.S., Korea, Philippines, and Thailand from the IFS of the IFM constitute our data set. Three-month interest rates on government Treasury note rates, or other three-month money market rates (based on availability), consumer price index, and the exchange rate (dollars per foreign currency) are the variables under consideration. The data are considered through December 1996, in order to avoid effects of currency problems that were developing in these emerging markets and culminated in the baht depreciation of the summer 1997. Real interest rate differentials are computed from the U.S. point of view. For example, the interest rate differential for Korea would be the short-term rate for Korea minus the U.S. three month treasury note rate. Similarly, the change in the value of the Korean won is computed the change in the dollar value of the won in three months, employing the actual spot won rate in three months. This computation is ex post because there are no reliable expected exchange rates available for most emerging markets. Furthermore, there are no formal futures or forward markets (and therefore, exchange rates) in these markets either. With the data set in place, regression equation described in equation equation (7) is estimated. Several tests are employed to ascertain the white noise properties of the regression residual e. If the uncovered interest parity holds, the regression residual is expected to be white noise. These tests are briefly explained below.

\section{Vector Autoregressive Models and Impulse Response Functions}

The main econometric tools used in this paper are simple regression analysis and the vector autoregressive technique (VAR). The former does not require a description. However, we briefly describe VAR modeling. VAR models are the best tools to investigate shock transmission since they provide information on impulse response analysis. A series of vector error correction models (VECM) constitute the mainstay of our empirical analysis. VAR or VECM models are particularly suitable for this type of a study because they allow for examining the effects of a shock to one endogenous variable on the remaining endogenous variables of the model.

Zellner and Palm (1974), Zellner (1979), and Palm (1983) show that any linear structural model can be written in the form of a vector autoregressive moving average multivariate time series model (VARMA) whose coefficients are combinations of the structural coefficients. These researchers show that under mild regularity conditions a VARMA model can be written as a VAR model. Therefore, a VAR model serves as a flexible approximation to the reduced form of any wide variety of simultaneous structural models. To paraphrase, the reduced forms of traditional simultaneous models are special cases of VAR models.

VAR models are typically smaller than structural models and therefore require less data. In addition they do not use economic theory in their specification. The procedure used in this paper is as follows. We use VAR models in conjunction with the Akaike's Information Criteria (AIC) to determine the dimensionality of equations of the system.

This system of equations can be written in compact matrix notation as follows:

$$
\left[\begin{array}{ll}
1-\alpha_{11}(L) & -\alpha_{12}(L) \\
-\alpha_{21}(L) & 1-\alpha_{22}(L)
\end{array}\right]\left[\begin{array}{l}
F P_{t} \\
R D_{t}
\end{array}\right]+\left[\begin{array}{l}
\beta_{1} \\
\beta_{2}
\end{array}\right]=\left[\begin{array}{l}
u_{1 t} \\
u_{2 t}
\end{array}\right]
$$


where $\alpha_{11}(L)$ through $\alpha_{22}(L)$ are n-th order scalar polynomials in the lag operator L, where $\alpha_{i j}(L) \sum_{k=1}^{m} a_{i j} L^{k}$, and $L^{k} \mathrm{x}^{t}=\mathrm{x}^{t-k}$, and $\mathrm{m}$ is the lag length specified. Variables $\mathrm{FP} t$ and $\mathrm{RD}{ }^{t}$ represent forward premium and interest rate differential, respectively, $\beta_{i}$, model constants, and $u_{t}=\left[u_{1 t} u_{2 t}\right]$ is a vector of white noise residuals process.

A final consideration in using the VAR model is the choice of the order of the process, p. Without a formal method, the selection of lag order in a VAR model will be arbitrary and could lead to specification error (See Fair and Schiller (1990), and Funke (1990)). Several criteria, similar to those used in the distributed lag models, are suggested to determine the model dimension (see Judge, et al. (1985) and Lutkepohl (1985)). In this paper, the minimum Akaike (1974) Information Criteria (AIC) determines the optimum lag length (see Judge, et al. (1988)). It can be shown that the GLS estimators of the coefficients are identical to the OLS estimators under the above assumption regarding the residuals.

VAR models are routinely used to perform impulse response analysis, which allow us to measure the various period impact of the $u_{t-i}$ on each variable. Impulse response analysis requires a vector moving average (VMA) representation of a VAR. The VMA allows us to trace out the time path of the various shocks on the variables of the VAR system. Consider the VMA process given by

$$
\left[\begin{array}{l}
F P_{t} \\
R D_{t}
\end{array}\right]_{=}\left[\begin{array}{l}
\bar{F} P \\
\bar{R} D
\end{array}\right]_{+}\left[\begin{array}{ll}
\phi_{11}(i) & \phi_{12}(i) \\
\phi_{21}(i) & \phi_{22}(i)
\end{array}\right]\left[\begin{array}{l}
\varepsilon_{F P t-i} \\
\varepsilon_{R D t-i}
\end{array}\right]
$$

The sets of coefficients $\phi_{k j}(i)$ are called the impulse response functions. For example $\phi_{12}(0)$ is the instantaneous impact of a one-unit change in $\varepsilon_{R D t}$ on FP $t$. Similarly, $\phi_{12}(1)$ is the one period response of $\mathrm{FP} t$ to one unit change in $\varepsilon_{R D t-1}$. The accumulated effect of unit impulses in $\varepsilon_{R D t}$ on FP ${ }^{t}$ for example, can be computed by summing the coefficients of the impulse response function. Thus, the effect of ${ }^{R D t}$ on the $\mathrm{FP}^{t}$ after n periods is given by $\sum_{i=0}^{n} \phi_{12}(i)$

To produce reliable VAR estimates and impulse response analysis, variables of the model are required to be stationary, i.e., not have unit roots. A brief discussion of this test follows.

\section{Unit Root Tests}

Table 1 reports the findings of the ADF (Dickey and Fuller (1979)) tests of unit root. The ADF entails estimating $\Delta \mathrm{x}^{t}=\alpha+\beta \mathrm{x}^{t-1}+\Sigma^{L=1} \gamma^{j} \Delta \mathrm{x}^{t-j}+{ }^{u_{t}}$ and testing the null hypothesis that $\beta=0$ versus the alternative of $\beta<0$, for any $\mathrm{x}$. The lag length $\mathrm{j}$ in the ADF test regressions are determined by the Akaike Information Criterion (AIC). Two variations of the ADF regressions are estimated: with trend and intercept and with no trend variable. The purpose of this approach is to insure that the test results are robust in the presence of drifts and trends. For the ADF tests the MacKinnon (1990) critical values are used. Accepting the null hypothesis means that the series under consideration is not stationary and a unit root is present. 


\section{Granger Causality Tests}

Once the stationarity of each series is verified, bivariate Granger causality tests are performed to investigate the causal relationship between the two variables. The standard Grange $(1969,1980)$ causality test examines whether past changes in one stationary variable $\mathrm{X}^{t}$ help predict current changes in another stationary variable $\mathrm{Y}^{t}$, beyond the explanation provided by past changes in $\mathrm{X}^{t}$ itself. If not, then $\mathrm{X}^{t}$ does not "Granger cause" $\mathrm{Y}^{t}$. By reversing the position of variables $\mathrm{x}$ and $\mathrm{y}$, the causality in the opposite direction is tested. More formally, let $\theta$ and $\psi$ represent the set of past values of $\mathrm{Y}$ and bivariate series $\mathrm{Y}^{t}$ and $\mathrm{X}^{t}$ together, respectively. That is

$\theta=\left(\mathrm{Y}_{\mathrm{t}-1}, \mathrm{Y}_{\mathrm{t}-1}, \ldots \mathrm{Y}_{\mathrm{t}-\mathrm{n}}\right)$,

$\psi=\left(\mathrm{Y}_{\mathrm{t}-1}, \mathrm{Y}_{\mathrm{t}-2}, \ldots \mathrm{Y}_{\mathrm{t}-\mathrm{n}}, \mathrm{X}_{\mathrm{t}-1}, \mathrm{X}_{\mathrm{t}-1}, \ldots \mathrm{X}_{\mathrm{t}-\mathrm{n}}\right)$.

Also, let $\sigma^{2}\left(\mathrm{Y}^{t} / \psi\right)$ and $\sigma^{2}\left(\mathrm{Y}^{t} / \theta\right)$ represent the prediction error of $\mathrm{R}^{t}$ at time $\mathrm{t}$ based on the past values of $\mathrm{Y}^{t}$ and $\mathrm{X}^{t}$, and based on the values of $\mathrm{Y}^{t}$ itself. If $\sigma^{2}\left(\mathrm{Y}^{t} / \psi\right)<\sigma^{2}\left(\mathrm{Y}^{t} / \theta\right)$, then the information contained in set $\theta$ improves the prediction of the current value of $\mathrm{x}$ compared with the information content of the set of past values of $\mathrm{x}$ alone. Therefore, we say $\mathrm{X}^{t}$ "Granger causes" $\mathrm{Y}^{t}$. If the above inequality does not hold, then $\mathrm{X}^{t}$ does not Granger cause $\mathrm{Y}^{t}$. Granger causality test is used because the evidence reported in Geweke et al. (1983) shows that it outperforms other causality tests in a series of Monte Carlo experiments. To test this causality we estimate equation (10),

$\mathrm{Y}^{t}=\alpha+\sum^{\beta}{ }^{\beta} \mathrm{Y}^{t-i}+\sum \gamma_{\mathrm{i}} \mathrm{X}^{t-i}+\mathrm{u}^{i}$

where $\mathrm{Y}^{t}$ and $\mathrm{X}^{t}$ are stationary time series. The hypothesis that $\mathrm{X}$ does not Granger cause $\mathrm{Y}$ is rejected if ${ }^{\gamma_{i}} \mathrm{~s}$ are jointly significant. For the purpose of our paper we first test whether budget deficits Granger cause the stock returns in each market. In order to test for this causality we need to determine the lag dimensions in the Granger causality regressions. In the absence of any theoretical justification for the lag dimension we allow the data to determine the lag length. Thus, the dimensionality of regressors in the second set of Granger causality regressions is determined by the Akaike and Schwartz criteria (AIC, SIC, respectively) given by the following:

$\mathrm{AIC}(\mathrm{n})=\ln S_{n}^{2}+2 \mathrm{n} / \mathrm{T}$

$\operatorname{SIC}(\mathrm{n})=\ln S_{n}^{2}+\mathrm{nln} \mathrm{T} / \mathrm{T}$

where $S_{n}^{2}$ is the Maximum likelihood estimator of the residual variance obtained from a model with lag length $\mathrm{n}$ and $\mathrm{T}$ is the number of valid observations. The objective is to select a lag length that minimizes AIC or SIC or both. Of the two criteria, SIC has superior large sample properties. Furthermore, SIC is asymptotically consistent, while SIC is biased toward an over-parameterized model. Thus, in cases where the two criteria do not concur on the lag structure, the model is chosen base on the SIC criterion. 


\section{BDS Statistic}

Brock, Dechert, and Scheinkman (BDS, 1987) employ the correlation integral to obtain a statistical test that has been shown to have strong power in detecting various types of nonlinearlity as well as deterministic patterns including chaos. BDS show that if $\mathrm{x}_{\mathrm{t}}$ is IID with a nondegenerate distribution,

$$
C^{M}(\varepsilon) \rightarrow C^{l}(\varepsilon)^{M} \text {, as } T \rightarrow \text { infinity }
$$

where $\mathrm{C}^{\mathrm{M}}(\varepsilon)$ is the correlation integral (to be described shortly) for fixed $\mathrm{M}$ and $\varepsilon$. Employing this property, BDS show that the statistic

$$
W^{M}(\varepsilon)=\sqrt{T}\left[C^{M}(\varepsilon)-C^{l}(\varepsilon)^{M}\right] / \sigma^{M}(\varepsilon)
$$

where $\sigma^{\mathrm{M}}$, the standard deviation of [·], has a limiting standard normal distribution under the null hypothesis of IID. $\mathrm{W}^{\mathrm{M}}$ is termed the BDS statistic. Nonlinearity will be established if $\mathrm{W}^{\mathrm{M}}$ is significant for a stationary series void of linear dependence. The absence of chaos will be suggested if it is demonstrated that the nonlinear structure arises from a known non-deterministic system. For instance, if one obtains significant BDS statistics for a stationary data series, but fails to obtain significant BDS statistics for the residuals or the standardized residuals from an estimated model, it can be said that the model under consideration explains the nonlinearity in the data, precluding low dimension chaos.

Brock, Hsieh and LeBaron (1993) examine the finite sample distribution of the BDS statistic and find the asymptotic distribution will well approximate the distribution of the statistic when: the sample has 500 or more observations; the embedding dimension is selected to be 5 or lower; and $\varepsilon$ is selected to be between 0.5 and 2 standard deviations of the data.

\section{Correlation Dimension}

Consider the stationary time series $\mathrm{x}_{\mathrm{t}}, \mathrm{t}=1 \ldots \mathrm{T}$. $^{1}$ One imbeds $\mathrm{x}_{\mathrm{t}}$ in an m-dimensional space by forming M-histories starting at each date $t: x_{t}^{2}=\left\{x_{t}, x_{t+1}\right\}, . ., x_{t}^{M}=\left\{x_{t}, x_{t+1}, x_{t+2}, \ldots x_{t+M-1}\right\}$. One employs the stack of these scalars to carry out the analysis. If the true system is $\mathrm{n}$-dimensional, provided $\mathrm{M} \geq 2 \mathrm{n}+1$, the $\mathrm{M}$-histories can help recreate the dynamics of the underlying system, if they exists (Takens (1984)). One can measure the spatial correlations among the M-histories by calculating the correlation integral.

For a given embedding dimension $\mathrm{M}$ and a distance $\varepsilon$, the correlation integral is given by

$$
C^{M}(\varepsilon)=\lim _{T \rightarrow \infty}\left\{\text { the number of }(\mathrm{i}, \mathrm{j}) \text { for which }\left\|x_{i}^{M}-x_{j}^{M}\right\| \leq \varepsilon\right\} / T^{2}
$$

where $1 . \mid$ is the distance induced by the norm. ${ }^{2}$ For small values of $\varepsilon$, one has $\mathrm{C}^{\mathrm{M}}(\varepsilon) \sim \varepsilon^{\mathrm{D}}$ where $\mathrm{D}$ is the dimension of the system (see Grassberger and Procaccia (1983)).

\footnotetext{
${ }^{1}$ It is known that nonstationary processes can generate low dimensions even when not chaotic (e.g, Brock and Sayers (1988). To rule out nonstationarity as a 'cause' for low dimension, one may difference the original series if it contains a unit root.

${ }^{2}$ In practice $\mathrm{T}$ is limited by the length of the data which in turn places limitations on the range of the values of $\varepsilon$ and $\mathrm{M}$ to be considered.
} 


\section{Spectral Analysis}

Another test that is helpful in detecting the properties of a time series is the spectral analysis. It is performed in the frequency domain. For a univariate covariance stationary process $x t$ with $E\left(x_{t}\right)=\mu$, the sample spectral density function is written as

$$
\hat{f}(\omega)=\frac{1}{\pi}\left\{\hat{\gamma}_{0}+2 \sum_{k=1}^{\infty} \hat{\gamma}_{k} \cos (\omega k)\right\}, 0 \leq \omega \prec \pi
$$

Where $\gamma_{\mathrm{k}}$ is the sample autocovariance. If $\mathrm{x}_{\mathrm{t}}$ is a white noise process (i.e., $\gamma_{0}=\sigma 2$ and $\gamma_{\mathrm{j}}=0$ for $\mathrm{j} \neq 0$ ), then $\mathrm{f}(\omega)$ is flat at $\sigma 2 / \pi$ for all $\omega \in[0, \pi]$. Similarly, for stationary AR (1) process $x_{t}, f(\omega)$ is monotonically decreasing or increasing depending in $\omega$ depending on the sign of the lagged coefficient of the $x_{t}$ in the AR (1) process. For the MA (1) process, $f(\omega)$ is also monotonically decreasing or increasing depending on the sign of the MA(1) coefficient.

\section{GARCH (1,1) Model}

To further investigate possible nonlinearities in the equation (7), we also employ a $\operatorname{GARCH}(1,1)$ formulation of the equation. This formulation allows for both autoregressive and moving average components in the heteroscedatic residual variance as follows:

$$
h_{t}=\alpha_{0}+\alpha_{1} \varepsilon_{t-1}^{2}+\beta_{1} h_{t-1}
$$

The GARCH $(1,1)$ representation of the equation is more appropriate if regression residuals fail to show the expected white noise properties or fit an ARMA process. Furthermore, if the autocorrelation of squared residuals from equation (7) are statistically significant, then a GARCH(1,1) model maybe called for.

\section{EMPIRICAL FINDINGS}

Table 1 provides the summary statistics for interest rate differential (DR) and the forward currency premium (FP). Standard deviation, skewness, kurtosis, and JB tests show that variables DR and FP are not normally distributed. However, the ADF tests of stationarity show ample evidence that these variables are stationary. Therefore, regression estimations based on these variables produce reliable results.

Having concluded that variables FP and DR are stationary, we estimate VAR models with appropriate lag order. An advantage of a VAR model over regression equations is that it does not impose a priori exogenoiety relationship on the variables. The first step in estimating the VAR model is determining the appropriate lag order. Judge et al. (1988) show that over- or under-parameterization of a VAR model may lead to spurious estimation results. The log likelihood ratio (LLR) test is employed for this purpose. Statistically significant LLR rejects the lag order which leads to that LLR value. According to Table 2, LLR is statistically significant for all lags up to 7, 7, and 8, for Korea, Philippines, and Thailand, respectively. Therefore the LLR test statistic rejects lag orders of 7, for two markets and 8 for the third. In the following, VAR models of orders 8 and 9 are specified and estimated.

Table 3 presents the findings of Granger block causality tests from estimated VAR models for the three economies. Interest rate differentials in two out of three markets Granger cause exchange rate depreciation, as predicted by the uncovered interest parity hypothesis. Only for Korea, the exchange rate does not respond to the short-run market forces. The rigidity of Korean currency may be a result of the central bank intervention in the currency markets. It also shows that for the period of this study the Korean financial markets are not fully integrated into the international financial system. Furthermore, market inefficiencies in emerging markets may contribute to the slow information transmission. It is well known that all of the above factors produce opportunities for interest arbitrage to persist for a long period of time, contrary to the underlying assumptions of the uncovered interest parity hypothesis. 
Table 4 presents the maximum likelihood estimation of equation (7) for each market. It shows that for two of the markets the coefficient of DR is negative and statistically significant. This finding means that the forward premium and rate differentials in both Korea and Philippines are negatively correlated, as predicted by the uncovered interest parity hypothesis. For example, if short-term real interest rates in these markets are higher than those of the U.S., then their exchange rates in fact depreciated as expected by the uncovered parity. However, for the uncovered parity to hold, the estimated $\alpha$ is expected to be statistically insignificant while $\beta$ is expected to be equal to one. The Wald test rejects the hypothesis that $\beta$ is one at the one percent level for all markets and the estimated intercept is statistically significant in two out of three cases. Therefore, it is concluded that the uncovered parity in strict sense does not hold in any of these emerging economies. For example, based on the uncovered interest parity hypothesis, a one percent interest rate differential between Korea and the U.S. would imply that the related currency would depreciate in the spot markets of the near future by one percent. This would require the interest rate coefficient to be one. Therefore it may be reasonable to assume that the EUDI is on average not zero and not randomly distributed. We devote the next table to report the results of testing for white noise properties in EUDI. The first test is BDS.

Table 5 reports the BDS statistic results for the EUDI for embedding dimensions 2 through 4 and $\varepsilon$ varying form $1 / 2$ to 2 . BDS statistics reported are significant at the 5 percent level. This finding indicates that a different linear or nonlinear model may be able to explain the pattern existing in the EUDI for the three markets. A possible model that may account for some of the potential nonlinearities is GARCH $(1,1)$ model.

Empirical findings reported thus far provide strong evidence against the hypothesis that EUDI for the three markets are randomly distributed white noise series. Thus, the BDS statistic provides further support for the conclusion that the strict uncovered interest parity hypothesis, based on the ex post observations, does not hold for the three emerging markets under investigation. In the following we fit a GRACH $(1,1)$ model to the uncovered parity relationship in the three emerging economies.

Table 6 reports the estimation results from the GARCH $(1,1)$ model presented above. The parameter estimates from a GARCH model remain quite consistent with those reported in Table 2. Furthermore, it is apparent from the variance equation that a $\operatorname{GARCH}(1,1)$ model explains existing nonlinearities in the relationship very well. The coefficients of the past shocks and variances in both equations are statistically significant at the one percent level.

The results of residual tests of the GARCH $(1,1)$ model are presented in the bottom panel of Table 3 . While the GARCH model has explained nonlinearities in the standardized residuals, there still are unexplained linear dependencies in the standardized residuals. This may show that the GARCH $(1,1)$ model, though an improvement over a linear one, still is not completely successful in explaining the relationship between exchange rates and interest rates in these economies. Furthermore, the empirical evidence presented above demonstrates the complexities of this relationship despite its simple textbook appearance. Our findings also suggest that the strict uncovered interest parity may not hold in many cases. There may be market and political complexities at work that may elude being captured by models of econometrics.

Returning to the impulse responses, Figures 1, 4, and 7 show that one standard deviation shock to the equation for interest rate differential for the three markets, affects exchange rates for several months. These graphs support the findings above. They verify that there is some relationship between interest rate differentials and exchange rates. However, this relationship may not be the one predicted by the uncovered interest parity hypothesis in its strict sense. In fact, if the uncovered parity existed, the duration of the effects of these shocks would be short and exchange rates quickly would rapidly revert to equilibrium with respect to the interest rates differentials. However, we find that in all cases the impulse responses are the strongest during the first few months.

Autocorrelation functions in figures 2, 5, and 8 indicate that the residuals from equation (7) for the three markets under study are not white noise as expected. Indeed, some form of AR, MA, or ARIMA model may explain the behavior of these residual series.

Bartlett, Tukey and Parzen estimates of spectral density functions of the standardized residuals from equation of the GARCH $(1,1)$ model of uncovered interest parity for the three markets are shown in figures 3,6 , and 9 . They 
corroborate that none of the sample spectral density functions are flat as would be expected in the case of white noise residuals. For instance, the contribution to the sample variance of the lowest frequency (such as business cycle frequencies) is much higher than the intermediate frequencies. Once again, the conclusion drawn from these graphs is that although the exchange rate and interest differentials for the three markets show some relationship, the uncovered parity theory is not supported.

There are a number of possible explanations. First, because of the inherent risk involved in uncovered investments, the excess nonzero uncovered differential is the excess return that compensates investors for the exchange rate risk. However, some studies show that the differential may be larger than the risk premium. Second, exchange rate markets may be inefficient. Then, differentials may show a consistent pattern. In that case, market participants construct models to predict the actual spot rates in the near future. Third, explanation is based on investor expectations. For example, if investors expect a large drop in future spot rates, many uncovered investments do not take place. However, as investors avoid uncovered investments, the actual spot exchange rates in the future firm up, resulting in positive uncovered differentials.

\section{SUMMARY AND CONCLUSIONS}

This paper investigates the validity of the uncovered interest parity for the three emerging markets of Korea, the Philippines, and Thailand. The objectives of the study are to provide more data on the efficiency of the currency markets of these economies. Such data may be useful to monetary and financial authorities of these economies, as well as investors, speculators, and import and export firms. Note that currency market information is one more indicator as to the efficiency and transparency on these markets. Long-term capital inflows into emerging economies are sensitive to exchange rate risks and the effects of interest rate and other macroeconomic variables on their exchange rate exposure. In this paper we test for the uncovered interest parity because futures markets for currencies of emerging markets such as these are not well developed. Furthermore, short- term exchange rate supply and demand are often dominated by the uncovered international investments.

Several statistical tests are applied in an attempt to detect evidence of uncovered interest parity. Our results show that uncovered IRP does not exist in any of the three Asian emerging markets tested here for post-1990 periods. We also find that there is strong evidence in two out of three markets that there is a negative relationship between the real interest differentials between the U.S. and the emerging markets of Thailand and the Phillipines, and the prevailing exchange rates of their currencies. Therefore, there is evidence that the currencies of higher interest rate emerging economies tend to depreciate in the forward market. However, our test results indicate that this relationship does not support the uncovered interest parity strictly and the currency markets in these nations are not fully efficient. Arbitrage opportunities remain for a longer periods than predicted by the uncovered interest parity. Furthermore, these abnormal gains are not random and could be predicted by a well designed econometric model. These findings are consistent with empirical findings surrounding uncovered interest parity for mature markets of the world.

The implications of these findings for hedge fund managers and other speculators in currency markets is that these investors do have the motivation to attempt to exploit pricing inefficiencies in Asian emerging markets. Also, since it is likely that other factors (besides interest rates) cause changes in the exchange rates of these markets, policymakers in these countries may want to focus on other causes in their monetary policy decisions.

\section{REFERENCES}

1. Abeysekera, S. and H. J. Turtle. (1995). Long-Run Relations in Exchange Markets: A Test of Covered Interest Parity, Journal of Financial Research, 18, 431-47.

2. Akaike, H. (1974). A New Look at Statistical Model Identification, IEEE Transactionson Automatic control, 19, 716-723.

3. Bakaert, G. and R. Hodrick. (1993). On Biases in the Measurement of Foreign Exchange Risk Premiums, The Journal of International Money and Finance, 12, 3-39. 
4. Brock, W. A., W. Dechert, and J. Scheinkman,. (1987). A Test of Independence Based on the Correlation Dimension, Unpublished Manuscript, University of Wisconsin, Madison, University of Houston, and University of Chicago.

5. Brock, W. A., D. A. Hsieh, and B. LeBaron. (1993). Nonlinear Dynamics, Chaos, and Instability: Statistical Theory and Economic Evidence, MIT Press, Cambridge, Massachusetts.

6. Brock, W. A. and C. L. Sayers. (1988). Is the Business Cycle Characterized by Deterministic Chaos? Journal of Monetary Economics, 22, 71-90.

7. Dickey, David A. and Wayne A. Fuller. Distribution of the Estimators for Autoregressive Time series with a Unit Root, Journal of the American Statistical Association, 74, no. 366, (June 1979), 427-3.

8. $\quad$ Enders Walter. Applied Econometric Time Series, edition, John Wiley: New York, 1995.

9. Fair Ray C. and Robert J. Schiller. Comparing Information in Forecasts from Econometric Models, The American Economic Review, 80, no. 3, (June 1990), 375-389.

10. Funke, Michael. Assessing the Forecasting Accuracy of Monthly Vector Autoregressive Models: The Case of five OECD countries, International Journal of Forecasting, 6, (1990), 363-378.

11. Geweke, John, Richard Meese, and Warren Dent. Comparing Alternative Tests of Causality in Temporal Systems. Journal of Econometrics, 21, no. 2, (February 1983), 161-94.

12. Granger, Clive, W. J. Investigating the Causal Relations by Econometric Models and Cross-Spectral Methods. Econometrica, 37, no.3, (July 1969), 424-38.

13. $\quad$---------------, Testing for Causality. Journal of Economic Dynamics and Control, 2, no. 4, (November 1980), 320-52.

14. Grassberger, P. and I. Procaccia. (1983). Application of Nonlinear Mapping Theory to Commodity Price Fluctuations, Journals of Economic Dynamics and Control, 13, 225-246.

15. Judge, George G., et al. (1988). Introduction to the Theory and Practice of Econometrics, 2nd edition, John Wiley: New York.

16. Judge, George G., W. E. Griffiths, R. Carter Hill, H. Lukepohl, and T. C Lee. (1985). Theory and Practice of Econometrics, 2nd edition, John Wiley: New York.

17. Liu, Peter and C. Maddala. (1992). Rationality of Survey Data and Tests for Market Efficiency in the Foreign Exchange Markets, Journal of International Money and Finance, 11, (2), 366-381.

18. Lutkepohl, Helmut. Comparison of Criteria for Estimating the Order of A Vector Autoregressive Process, Journal of Time Series Analysis, 6, no. 1, (1985), 35-52.

19. MacKinnon, J.G. (1990). Critical Values for Cointegrating Tests, University of California at San Diego, discussion paper $90-4$.

20. Palm, Franz. Structural Econometric Modelling and Time Series Analysis, in: Arnold Zellner, Applied Time Series Analysis of Economic Data, Economic Research Report ER-5 (Us Department of Commerce, Washington, DC), 1983, 199-233.

21. Rhee, Ghon, S. and Rosita P. Chang. (1992). Intraday Arbitrage Opportunities in Foreign Exchange and Eurocurrency Markets, Journal of Finance, XLVII, (2), 363-379.

22. Takens, F. (1984). On the Numerical Determination of the Dimension of an Attractor, in Dynamical Systems and Bifurcations, Lecture Notes in Mathematics, Springer-Verlag Publishing, Berlin.

23. Van Horne, James C. (1998). Financial Market Rates and Flows, $5^{\text {th }}$ Edition, Prentice Hall, Upper Saddle River, New Jersey.

24. Zellner Arnold. Statistical Analysis of Econometric Models, Journal of the American Statistical Association, 74, no. 367, (September 1979), 628-643.

25. - -------and F. Palm. Time Series Analysis and Simultaneous Equation Econometric Models, Journal of Econometrics, 2, no.1, (May 1974), 17-54. 
Table 1

Summary Statistics

\begin{tabular}{|l|c|c|c|c|c|c|}
\hline & \multicolumn{2}{|c|}{ Korea } & \multicolumn{2}{c|}{ Philippines } & \multicolumn{2}{c|}{ Thailand } \\
\hline & RD & FP & RD & FP & RD & FP \\
\hline Mean & 7.94 & -0.008 & 8.30 & -0.016 & 4.26 & -0.006 \\
\hline Standard Deviation & 2.95 & 0.057 & 6.36 & 0.049 & 3.71 & 0.061 \\
\hline Skewness & 1.49 & -4.67 & 1.26 & -1.74 & 1.28 & -0.61 \\
\hline Kurtosis & 5.71 & 38.40 & 5.59 & 8.46 & 5.07 & 16.40 \\
\hline JB & $137.32^{* * *}$ & $11287.61^{* * *}$ & $151.43^{* * *}$ & $485.90^{* * *}$ & $78.94 * * *$ & $1320.13^{* * *}$ \\
\hline ADF WO/Trend & $-3.87 * *$ & $-6.28^{* *}$ & $-2.93^{* *}$ & $-6.07 * *$ & $-2.89^{* *}$ & $-5.35^{* * *}$ \\
\hline ADF W Trend & -2.97 & $-6.37^{* * *}$ & -3.05 & $-6.06^{* * *}$ & -2.95 & $-5.46^{* * *}$ \\
\hline
\end{tabular}

Notes: JB is theJaqus-Bera test of normality. Significant JB rejects normal distribution. Lag orders for ADF chosen based on AIC, are 4,2 , and 3, for DR, and 4 for FP, respectively for Korea, Philippines, and Thailand.

**,*** Significant at the 5 , and 1 percent levels, respectively.

Table 2

Loglikelihood Ratio Test of VAR Order Selection

\begin{tabular}{|c|c|c|c|}
\hline & Korea & Philippines & Thailand \\
\hline $\mathbf{1 2}$ & -- & -- & - \\
\hline $\mathbf{1 1}$ & 6.47 & 10.27 & 1.45 \\
\hline $\mathbf{1 0}$ & 9.57 & 15.96 & 5.16 \\
\hline $\mathbf{8}$ & 18.91 & 18.92 & 8.49 \\
\hline $\mathbf{7}$ & 23.66 & 21.79 & $34.44^{* * *}$ \\
\hline $\mathbf{6}$ & $120.12^{* * * *}$ & $47.50^{* * *}$ & $37.20^{* *}$ \\
\hline $\mathbf{5}$ & $128.79^{* * * *}$ & $57.21^{* * * *}$ & $53.08^{* * * *}$ \\
\hline $\mathbf{3}$ & $151.49^{* * * *}$ & $72.06^{* * *}$ & $61.02^{* * * *}$ \\
\hline $\mathbf{2}$ & $189.62^{* * * *}$ & $100.10^{* * * *}$ & $88.52^{* * *}$ \\
\hline $\mathbf{1}$ & $219.92^{* * * *}$ & $134.89^{* * * * *}$ & $96.72^{* * * *}$ \\
\hline
\end{tabular}

Notes: List of variables included in the unrestricted VAR: FP, ED, trend and intercept. The likelihood ratio is $\chi^{2}$ distributed with appropriate degrees of freedom determined by the lag order.

Significant at the 1 percent level.

Table 3

LR Test of Block Granger Non-Causality in the VAR

H0: Interest Rate differentials do not Granger Cause Exchange Rate Variations

\begin{tabular}{lc}
\hline Korea & 1.34 \\
Philippines & $10.59^{* * *}$ \\
Thailand & $50.04^{* * *}$
\end{tabular}

Thailand $50.04^{* * * *}$

H0: Exchange Rate Variations do not Granger Cause Interest Rate differentials

\begin{tabular}{lc}
\hline Korea & $110.53^{* * * *}$ \\
Philippines & $31.40^{* * * *}$ \\
Thailand & $38.60^{* * *}$
\end{tabular}

Notes: Block causality tests are performed based on VAR models with orders 8, 8,9, for Korea, Philippines and Thailand, respectively.

**** Significant at the 1 percent level. 
Table 4

Maximum Likelihood Estimator of Equation (7)

\begin{tabular}{|c|c|c|c|c|c|}
\hline & $\boldsymbol{\alpha}$ & $\boldsymbol{\beta}$ & $\mathbf{R 2}$ & LL & Wald \\
\hline Korea & $0.108^{* * * *}$ & $-0.012^{* * * *}$ & 0.65 & 398.39 & $232966^{* * * *}$ \\
\hline Philippines & $(4.67)$ & $(6.05)$ & & & \\
\hline & $0.039^{* * * *}$ & $0.003^{* * * *}$ & 0.62 & 576.90 & $1186444^{* * * *}$ \\
\hline Thailand & $(3.23)$ & $(3.18)$ & & & \\
\hline & 0.011 & $0.84 \mathrm{E}-3$ & 0.56 & 310.03 & $546658^{* * * *}$ \\
\hline
\end{tabular}

Notes: Exact AR(1) Inverse Interpolation Method Converged after 8,7, and 6 iterations for Korea, Philippines, and Thailand, respectively. Wald Statistic $\left(\chi^{2}\right)$ with one degree of freedom) tests the restriction for the Wald test that the coefficient of DR=1.

**** Significant at the 1 percent level.

Table 5

BDS Statistics

\begin{tabular}{|c|c|c|c|c|c|}
\hline \multicolumn{3}{|c|}{ Panel A: Korea } & \multicolumn{3}{|c|}{$\mathbf{M}$} \\
\hline$\varepsilon / \sigma$ & & 2 & 3 & 4 & 5 \\
\hline 0.5 & 0.043 & 19.85 & 21.35 & 22.68 & 24.72 \\
\hline 1.00 & 0.087 & 13.26 & 13.62 & 13.33 & 12.97 \\
\hline 1.50 & 0.130 & 10.22 & 10.56 & 10.72 & 10.48 \\
\hline 2.00 & 0.174 & 9.62 & 10.02 & 10.33 & 10.18 \\
\hline \multicolumn{6}{|c|}{ Panel B: Phillipines } \\
\hline 0.5 & 0.70 & 13.85 & 14.75 & 15.48 & 16.11 \\
\hline 1.00 & 0.14 & 15.18 & 16.37 & 17.80 & 19.31 \\
\hline 1.5 & 0.21 & 13.63 & 14.16 & 14.62 & 14.91 \\
\hline 2.00 & 0.28 & 13.21 & 12.78 & 12.54 & 12.20 \\
\hline \multicolumn{6}{|c|}{ Panel C: Thailand } \\
\hline 0.5 & 0.045 & 13.74 & 14.45 & 15.80 & 17.42 \\
\hline 1.0 & 0.09 & 13.03 & 12.73 & 12.55 & 12.85 \\
\hline 1.5 & 0.135 & 12.59 & 12.33 & 11.95 & 11.74 \\
\hline 2.00 & 0.18 & 11.61 & 11.29 & 10.99 & 10.71 \\
\hline
\end{tabular}

Notes: BDS statistics for all embedding dimensions are statistically significant at the 5 percent level.

Table 6

GARCH(1,1) Models

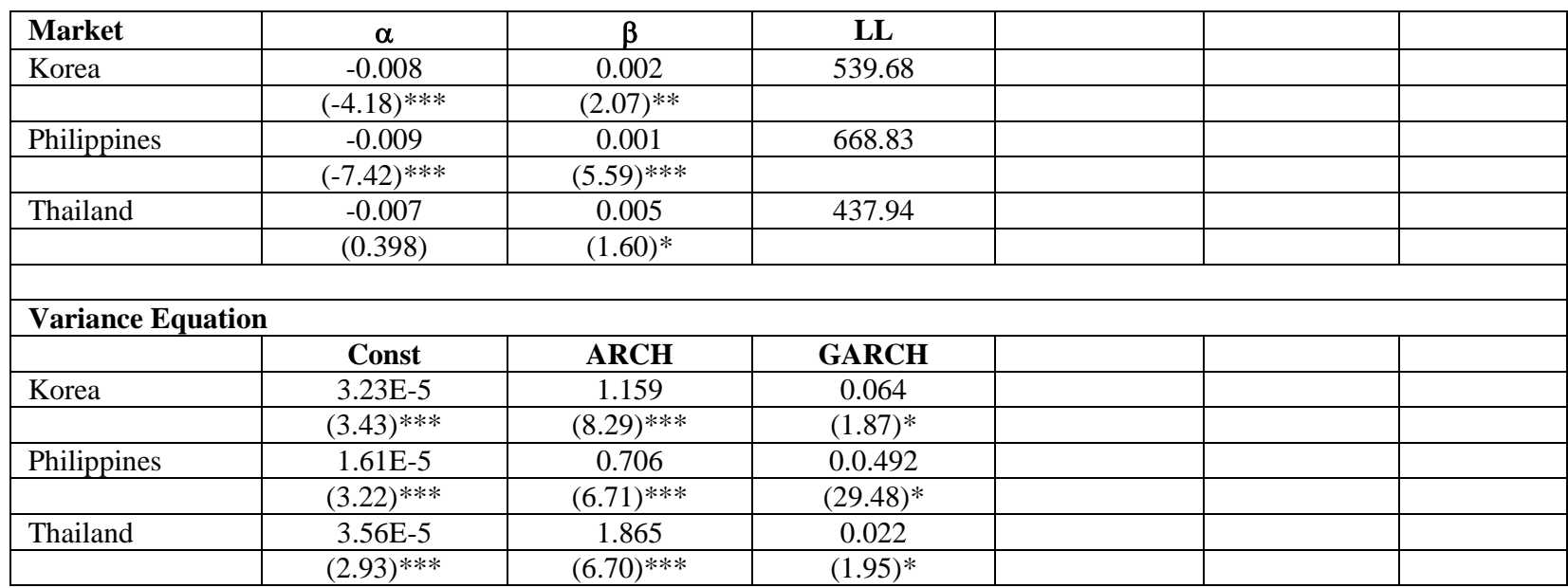




\begin{tabular}{|c|c|c|c|c|c|c|}
\hline \multicolumn{7}{|c|}{ Standardized Residual Tests } \\
\hline Market & $\mathbf{Q}(24)$ & $Q^{2}(24)$ & ADF & $\mathbf{P P}$ & JB & LM \\
\hline Korea** & $298.73 * * *$ & 31.16 & $-5.58 * * *$ & $-5.45 * * *$ & $7.87 * * *$ & $23.58 * * *$ \\
\hline Philippines** & $329.52 * * *$ & 12.96 & $-7.87 * * *$ & $-7.87 * * *$ & $6.76 * * *$ & $4.95 * *$ \\
\hline Thailand** & $46.70 * * *$ & 2.44 & $-9.20 * * *$ & $-9.03 * * *$ & $320.97 * * *$ & 0.065 \\
\hline
\end{tabular}

Notes:

${ }^{* * *},{ }^{* *},{ }^{*}$ represent significance at 1,5 , and 10 percent levels. The variance of the $\operatorname{GARCH}(1,1)$ model is written as

$$
\sigma^{2}=\alpha_{0}+\alpha_{1} \varepsilon_{t-1}^{2}+\alpha_{2} \sigma_{t-1}^{2}
$$

where $\varepsilon$ is the residual from equation (7). The results are based on expected future spot rates based on ex ante actual data.

\section{APPENDIX 1 \\ Simulated Critical Values for the BDS Test Statistic}

The figures represent the simulated values of the BDS statistic from Monte Carlo simulations of 2000 observations each. The simulations generated the 250 replications of the GARCH model $\left(\alpha_{1}=.10, \beta_{1}=.80\right)$, the exponential GARCH model $\left(\alpha_{1}=.05, \alpha_{2}=.05\right.$, $\left.\beta_{1}=.80\right)$, and the asymmetric component model $(\alpha=.05, \beta=.10, \rho=.80, \phi=.05)$. BDS statistics for four embedding dimensions and $\varepsilon=0.5$, $1,1.5$ and 2 standard deviations of the data were then computed for the $250 \times 3$ simulated series. The critical values represent the $97.5^{\text {th }}$ and $2.5^{\text {th }}$ percentile of the distribution of the simulated statistics.

$\varepsilon / \sigma$

\begin{tabular}{llll}
\hline 0.5 & 1.0 & 1.5 & 2.0
\end{tabular}

M

GARCH $(1,1)(97.5 \%$ critical values $)$

\begin{tabular}{lllll}
2 & 1.62 & 1.53 & 1.42 & 1.25 \\
3 & 1.76 & 1.63 & 1.45 & 1.44 \\
4 & 2.35 & 2.21 & 2.16 & 1.97 \\
5 & 2.42 & 2.28 & 2.25 & 2.10 \\
\hline
\end{tabular}

Exponential GARCH (97.5\% critical values)

\begin{tabular}{|c|c|c|c|c|}
\hline 2 & 2.75 & 2.54 & 2.10 & 1.83 \\
\hline 3 & 3.30 & 3.07 & 2.42 & 2.38 \\
\hline 4 & 3.48 & 3.31 & 2.66 & 2.56 \\
\hline 5 & 3.66 & 3.47 & 2.97 & 2.61 \\
\hline \multicolumn{5}{|c|}{ Asymmetric Component GARCH ( $2.5 \%$ critical values) } \\
\hline 2 & -2.86 & -2.29 & -1.78 & -1.74 \\
\hline 3 & -3.51 & -2.89 & -2.49 & -2.26 \\
\hline 4 & -3.64 & -3.01 & -2.81 & -2.55 \\
\hline 5 & -3.67 & -3.12 & -3.08 & -2.64 \\
\hline \multicolumn{5}{|c|}{ Asymmetric Component GARCH (97.5\% critical values) } \\
\hline 2 & 1.40 & 1.13 & 1.02 & 0.80 \\
\hline 3 & 1.47 & 1.27 & 1.17 & 0.93 \\
\hline 4 & 1.62 & 1.28 & 1.22 & 1.00 \\
\hline 5 & 1.82 & 1.40 & 1.31 & 1.07 \\
\hline
\end{tabular}


Figure 1: Korea

Generalized Impulse Responses to one Standard Error Shock in the Equation for Interest Rate Differentials

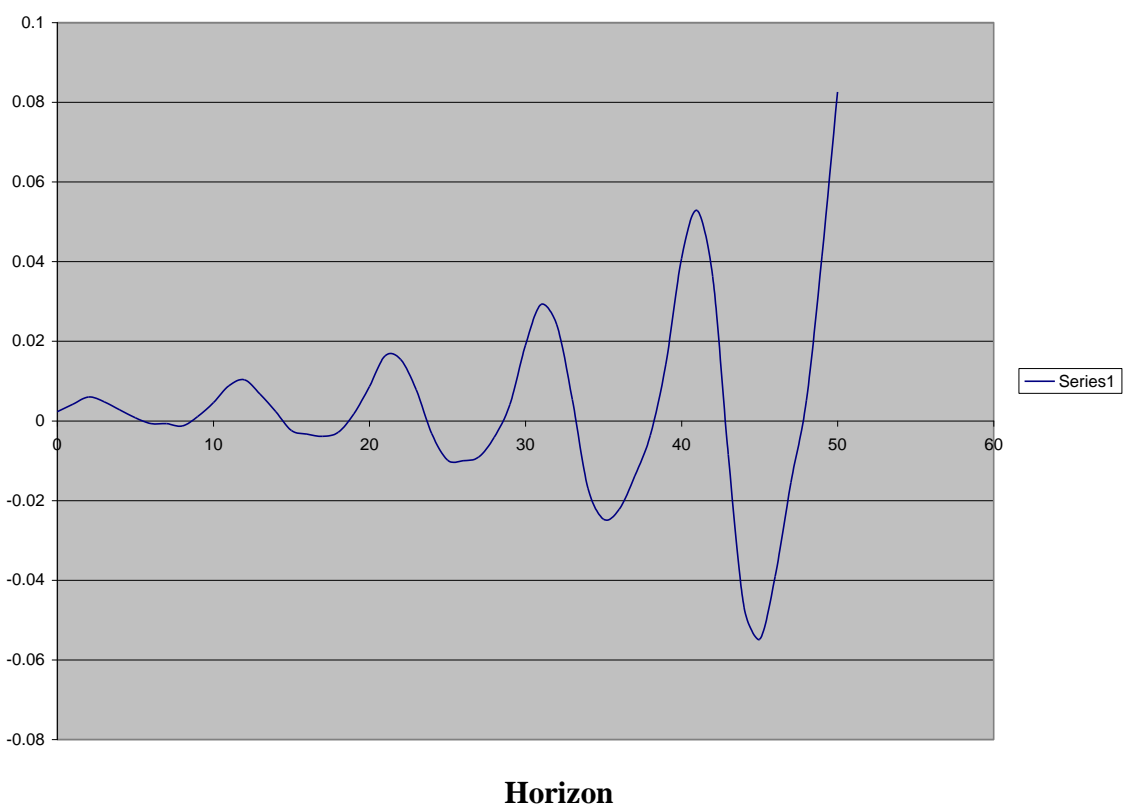

Figure 2: Korea

Autocorrelation Function of Residuals

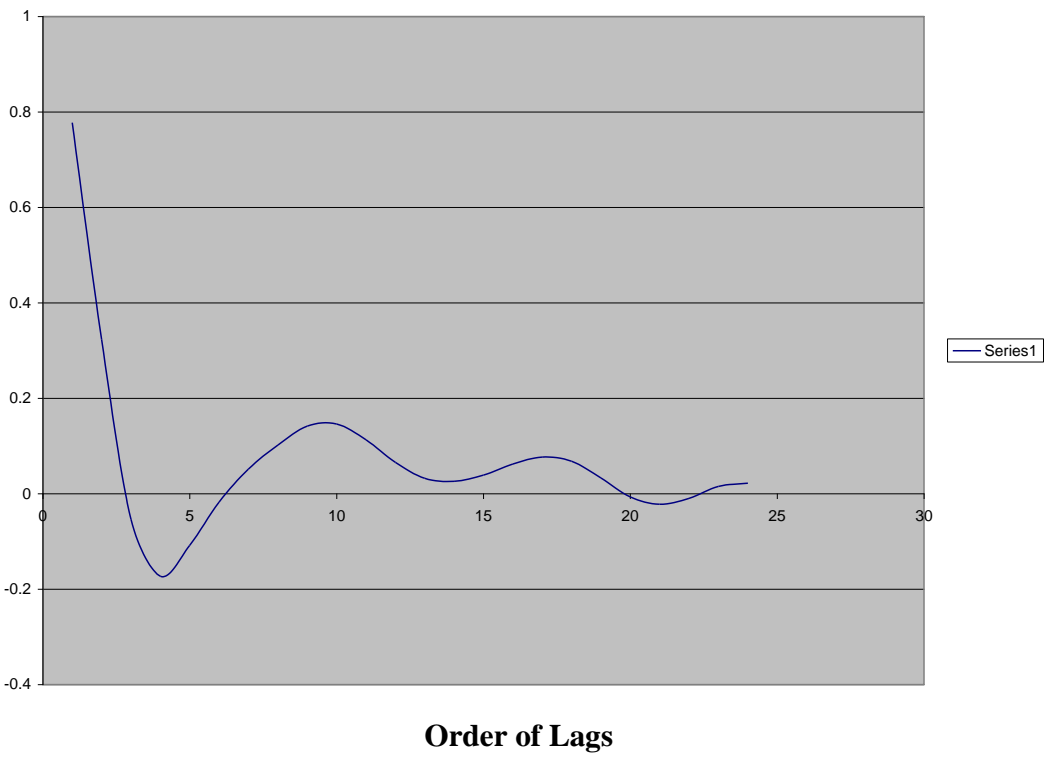


Figure 3: Korea Various Estimates of Standardized Spectral Density of Standardized Residuals

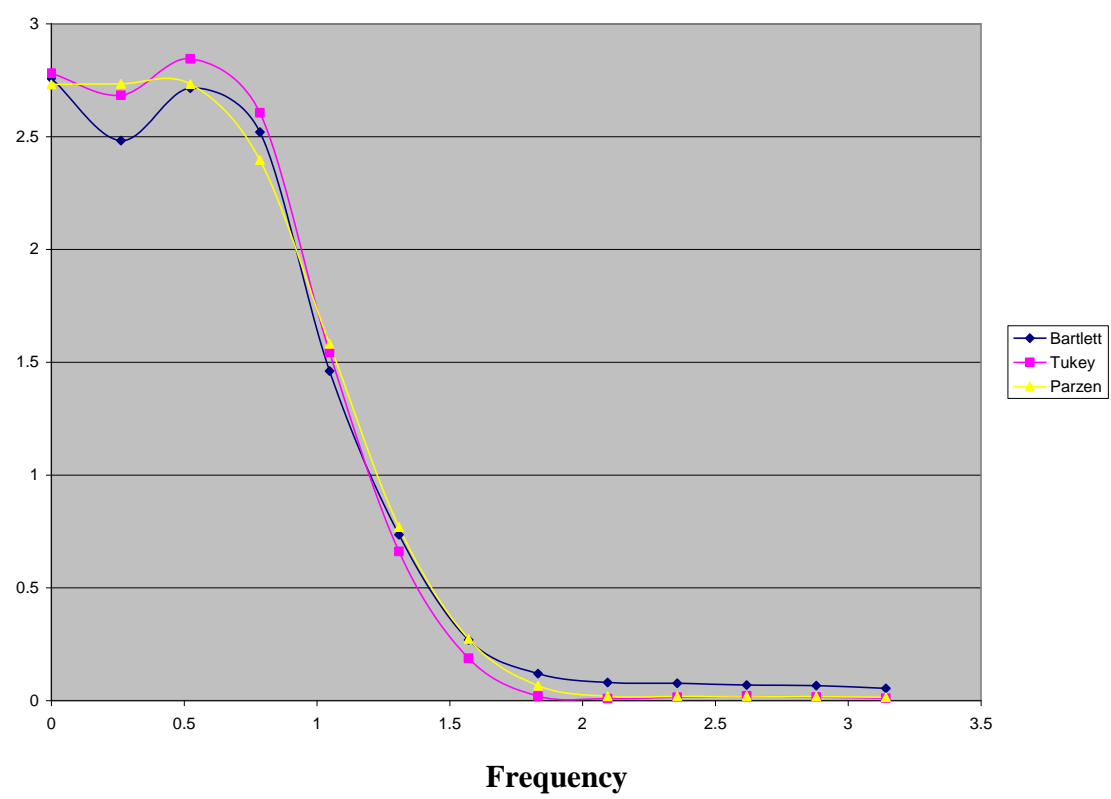

Figure 4: Philippines

Generalized Impulse Responses to one Standard Error Shock in the Equation for Interest Rate Differentials

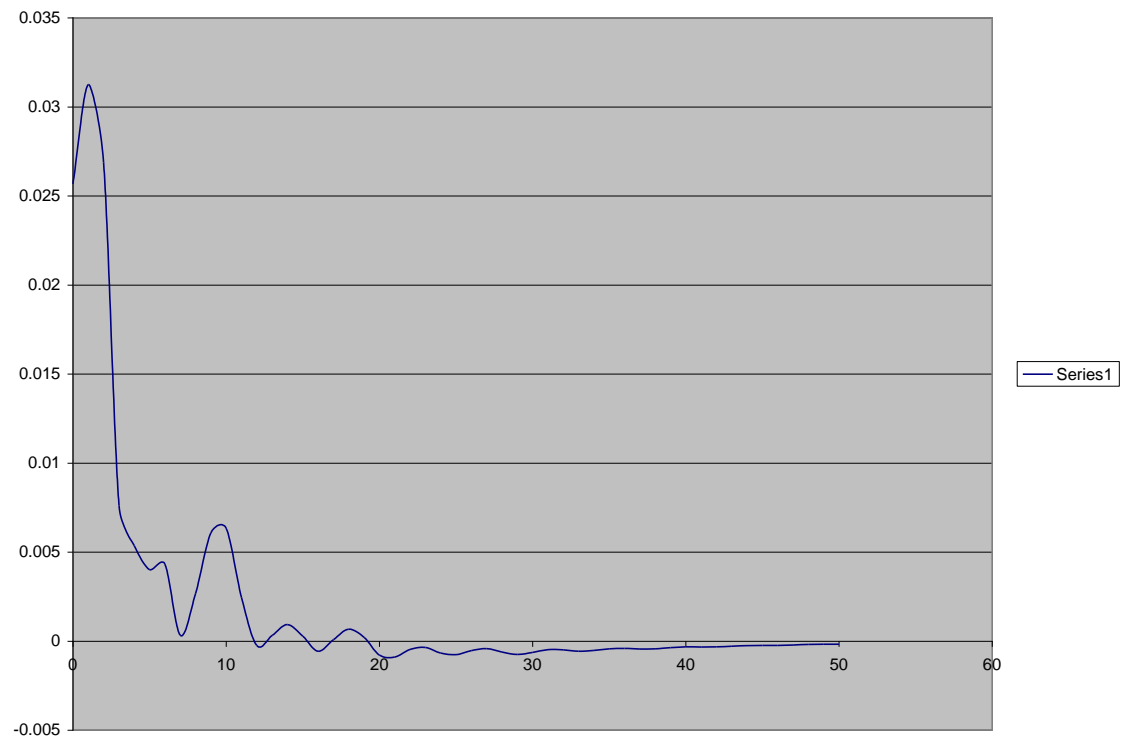

Horizon 
Figure 5: Philippines

Autocorrelation Function of Residuals

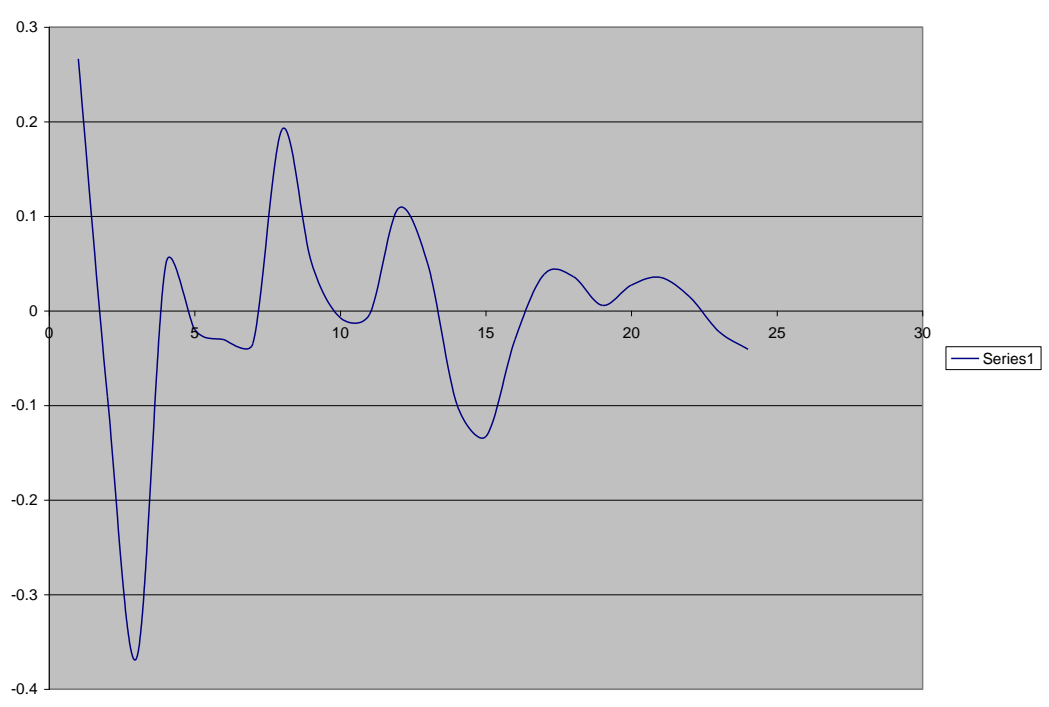

Order of Lags

Figure 6: Philippines

Various Estimates of Standardized Spectral Density of Standardized Residuals

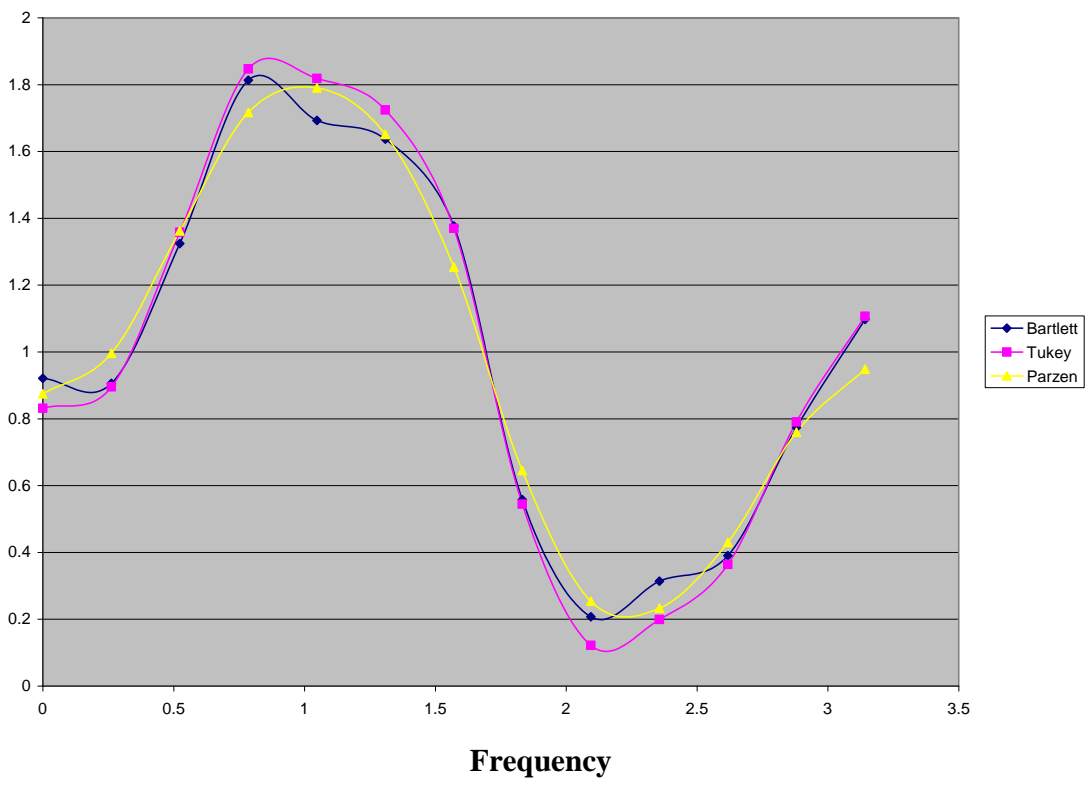


Figure 7: Thailand

Generalized Impulse Responses to one Standard Error Shock in the Equation for Interest Rate Differentials

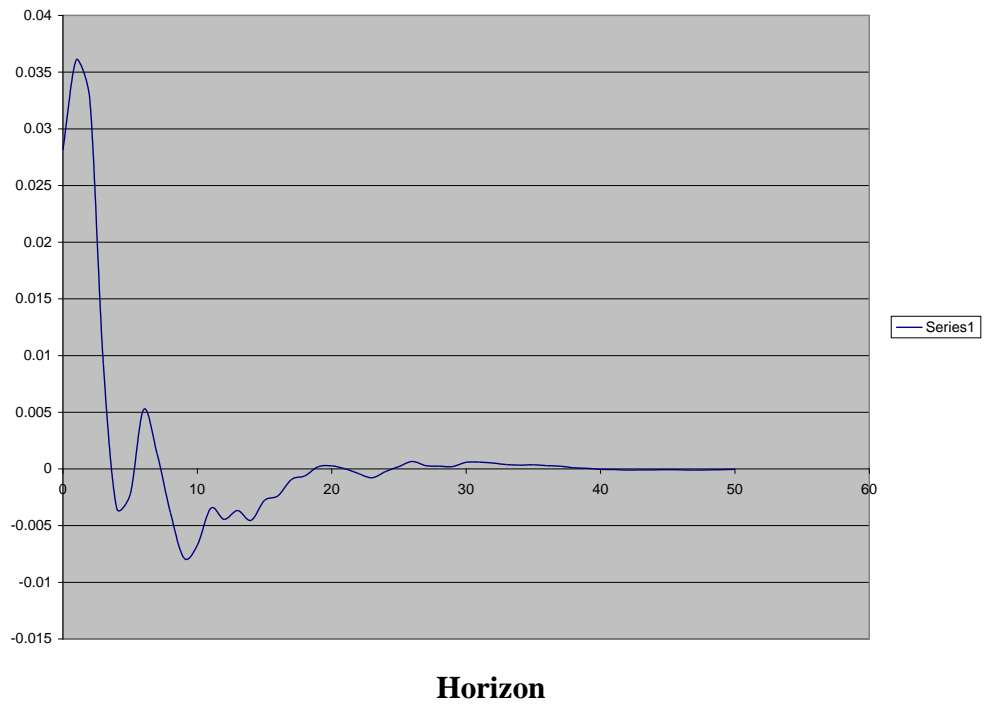

Figure 8: Thailand

Autocorrelation Function of Residuals

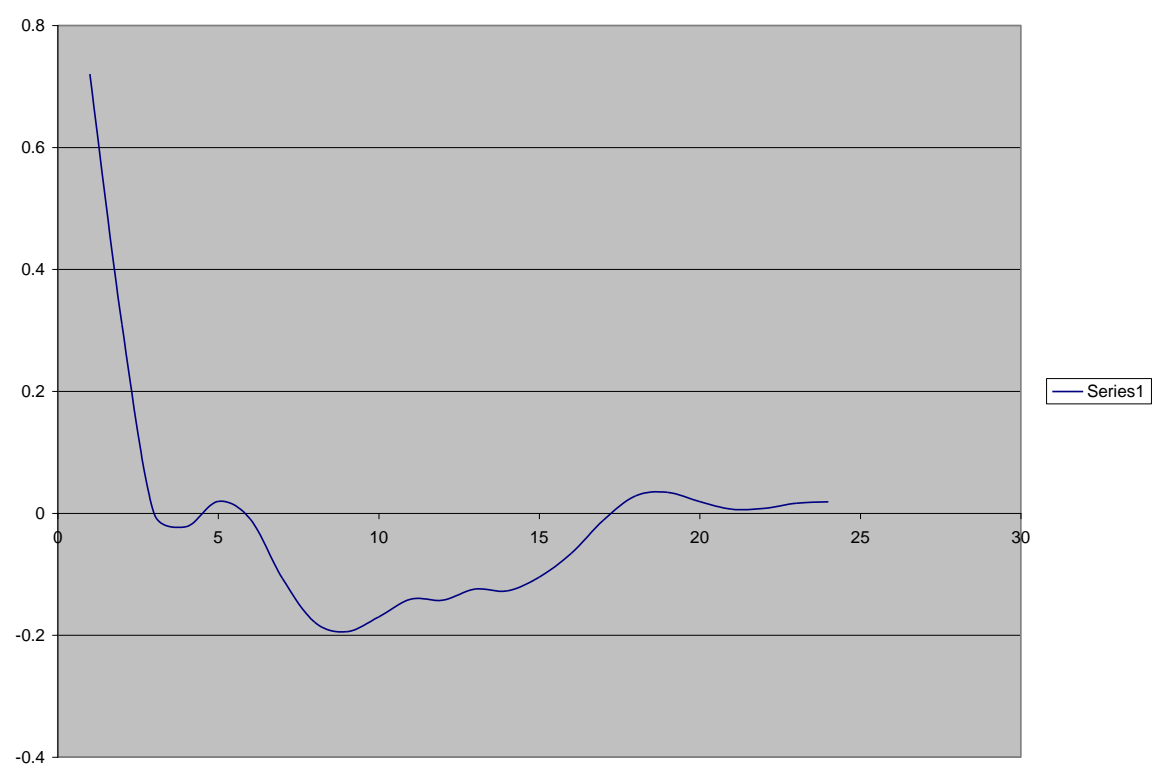

Order of Lags 
Figure 9: Thailand

Various Estimates of Standardized Spectral Density of Standardized Residuals

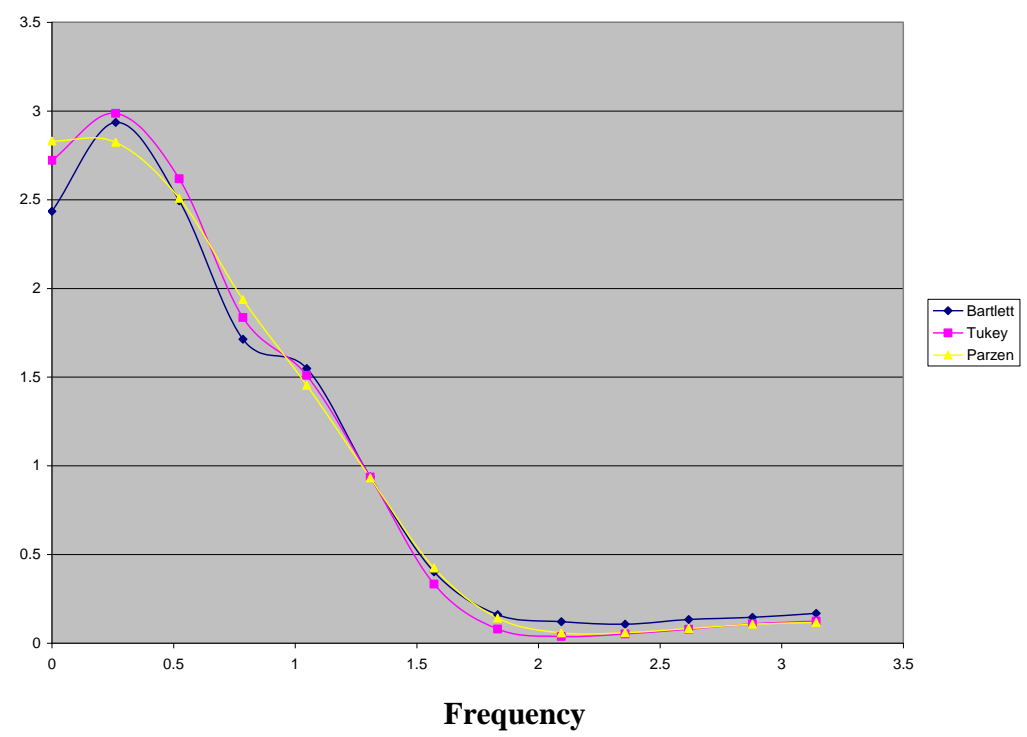

${ }^{1}$ Because estimated VAR models are underidentified, an identification restriction, the Choleski decomposition, is usually imposed. Choleski decomposition imposes a potentially important asymmetry on the system. Thus, changing the order of variables in impulse response analysis could produce different impulse responses (see Enders 1995). We choose deficits as the first variable because we are testing the hypothesis that deficits are causing stock returns. 
International Business \& Economics Research Journal - February 2007

Volume 6, Number 2

NOTES 